\title{
Limitation and good practices for breakage of cold chain on cos lettuce (Lactuca sativa var. longifolia)
}

\author{
Damorn Bundhurat ${ }^{1,3 *}$, Pichaya Poonlarp ${ }^{2,3}$, Viboon Changrue ${ }^{1,3}$, Danai Boonyakiat ${ }^{3}$, \\ Nadthawat Muenmanee ${ }^{3,5}$, Chaipichit Chuamuangphan ${ }^{3,4}$, and Warintorn Maneewan ${ }^{5}$ \\ ${ }^{1}$ Chiang Mai University, Faculty of Engineering, Department of Mechanical Engineering, 239 Huay \\ Kaew Road, Muang District, Chiang Mai 50200, Thailand \\ ${ }^{2}$ Chiang Mai University, Faculty of Agro-Industry, Division of Food Engineering, Chiang Mai 50100, \\ Thailand \\ ${ }^{3}$ Ministry of Higher Education, Science, Research and Innovation, Postharvest Technology Innovation \\ Center, 238 Thanon Si Ayutthaya, Thung Phaya Thai, Ratchathewi, Bangkok 10400, Thailand \\ ${ }^{4}$ Chiang Mai Royal Project Produce Center, The Royal Project Foundation, 243 Moo 3 Muang District, \\ Chiang Mai 50100, Thailand \\ ${ }^{5}$ Chiang Mai University, Faculty of Agriculture, Postharvest Technology Research Center, 239 Huay \\ Kaew Road, Muang District, Chiang Mai 50200, Thailand
}

\begin{abstract}
An effect of breaking the cold chain on cos lettuce (Lactuca sativa var. longifolia) had been studied in this research. Cos lettuce was taken under cold chain system at $4^{\circ} \mathrm{C}$. Imitating the exposure to high temperature in hot country, cos lettuce was put out in the $25,30,35$, and $40^{\circ} \mathrm{C}$ atmosphere for 15, 30, 45 and $60 \mathrm{~min}$. Product life, weight loss percentage, change of colour and chlorophyll content were measured to investigate quality degradation of cos lettuce. The limitation and good practices cos lettuce which had to go through cold chain breakage were acquired. From the results, it is recommended that cos lettuce should not exposed to temperature higher than $25^{\circ} \mathrm{C}$ for longer than $30 \mathrm{~min}$ in order to maintain acceptable quality and freshness close to absolute cold chain, considered from degradation of weight, colour and chlorophyll. Degree of temperature had influences on degrading levels of cos lettuce. Exposing to temperature higher than $35^{\circ} \mathrm{C}$ would degrade its quality and freshness and reduce storage life and should be avoid in any cases.
\end{abstract}

\section{Introduction}

A cold chain or temperature controlled supply chain provides the essential facilities and methods required to maintain the quality and quantity of foods [1]. In many countries, transporting vegetable products under the cold chain system has become a standard process of producing high-profit vegetables. The goal is to maintain the quality of the produce at a high level and prolong shelf life. Cos lettuce is one of the high-profit vegetable in Thailand which is treated under cold chain system during transporting. The process of keeping the

* Corresponding author: damorn.b@cmu.ac.th 
vegetable at low temperature requires continuity from origin to the selling place. Once the vegetable is damaged from heat, it is not possible to be restored to its original quality. Management of continuity of low temperature environment, there are steps that can be difficult to do so, such as moving vegetables from the cold room to the transportation truck or moving vegetables from the transportation truck to the distribution refrigerated shelf. A discontinuity of cold chain can severely damage the vegetable in the area that has high atmospheric temperature. This research intends to study the limitation of time and temperature of broken continuity of cold chain in order to maintain the quality of cos lettuce. The physical and chemical indicators will be investigated on cos lettuce that goes under discontinuity of cold chain at different periods of time and temperatures. The impact of interruption in the cold chain will provide information to set up the best practice when discontinuity of cold chain occurs.

\section{Methods of experiment}

The objective of this experiment was to set up the discontinuity of cold chain on cos lettuce at different time periods and temperatures. The investigate its change of physical and chemical properties which could indicates the quality of the cos lettuce, including weight loss, colour, and chlorophyll. Product life of cos lettuce was also investigated. Figure 1 showed the procedure of the experiment.

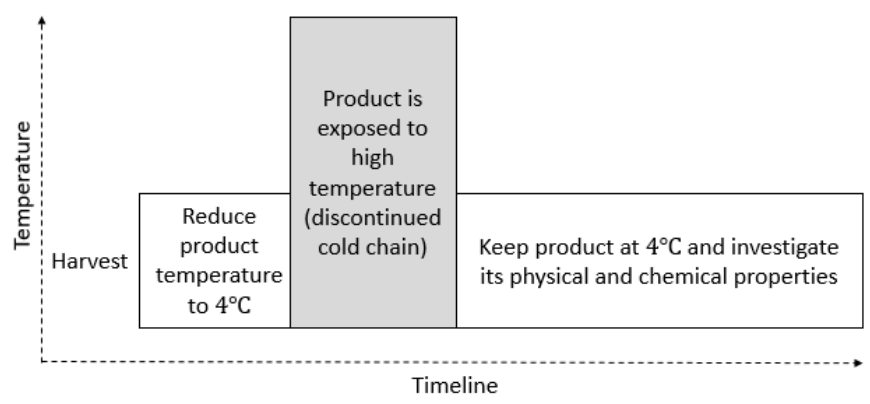

Fig. 1. Procedure of the experiment.

High temperature exposure conditions (discontinued cold chain) were set up to imitate atmospheric temperature in Thailand. Three repetitions were used in each condition as follows;

- Controlled sample (not exposed to high temperature)

- $\quad$ Exposed temperature $25^{\circ} \mathrm{C}$. Exposed time 15, 30, 45, 60 min

- $\quad$ Exposed temperature $30^{\circ} \mathrm{C}$. Exposed time 15, 30, 45, $60 \mathrm{~min}$

- $\quad$ Exposed temperature $35^{\circ} \mathrm{C}$. Exposed time 15, 30, 45, 60 min

- Exposed temperature $40^{\circ} \mathrm{C}$. Exposed time 15, 30, 45, $60 \mathrm{~min}$

Physical and Chemical properties were investigated as follows;

- Evaluate appearance of cos lettuce for shelf life until the product is considered spoil.

- Repeat experiment 3 times for weight loss and chlorophyll measurement.

- Repeat experiment 10 times for colour measurement.

Materials and measuring apparatus

1. Cos lettuce (packed in plastic bag)

2. Thermocouple: Lutron BTM-4208SD 12 channels 
3. Chroma meter: Minolta CR-300 with probe CR-310

Methods and equations

1. Percentage of fresh weight loss

The method for calculate percentage of weight loss refers to Tao et al., 2006[2].

Weigh vegetables using 2 decimal places scales and calculate the percentage.

Weight loss percentage $=\frac{\text { weight before storage }- \text { weight after storage } \times 100 \%}{\text { weight before storage }}$

2. Colour measurement of vegetables

Colour of each sample will be measure on leaf area. Each sample will be measured 2 positions. 10 samples are used for repetition. The Chroma meter used in this experiment is Minolta CR-300 with CR-310 probe. The results will be shown as $\mathrm{L} *$, Chroma and Hue angle according to CIELAB standard.

3. Determination of the amount of chlorophyll

The method to find amount of chlorophyll is by means of Witham, 1971[3].

4. Product life

Physical and appearance evaluation of cos lettuce from 5 trained assessors to determine of acceptance for consumer.

\section{Results and discussion}

\subsection{Controlled samples}

After harvesting, cos lettuce was put into cold chain system at $4^{\circ} \mathrm{C}$ approximately on the harvesting day and maintained under cold supply chain according to Chiang Mai Royal Project Produce Center's procedure. The packaging process was finished by the latter day and the products were brought into the experiment. Controlled samples could be kept for 5 days until they are considered spoil. Weight loss (Figure 2) increased approximately by $1 \%$ each day. Figure 3 showed that cos lettuce had been able to produce chlorophyll for 2 days after starting experiment. The amount of chlorophyll started to decrease on day 3 and 4 (noted that the amount of chlorophyll depended on product conditions and could be different in each sample). Consider the change of colour in Figure. $4 \mathrm{a}$ and $4 \mathrm{~b}, \mathrm{~L} *$ and Chroma values tended to increase on day 3 to 5, while the hue angle (Figure 4c) decreased. This indicated that colour of cos lettuce's leaf faded and turned slightly yellow over time. The objective of this experiment was to set up the discontinuity of cold chain on cos lettuce at different time periods and temperatures. The investigate its change of physical and chemical properties which could indicates the quality of the cos lettuce, including weight

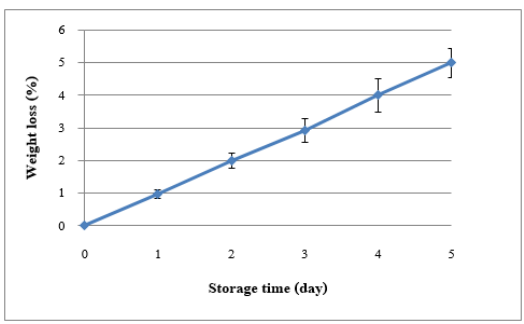

Fig. 2. \% weight loss of controlled samples.

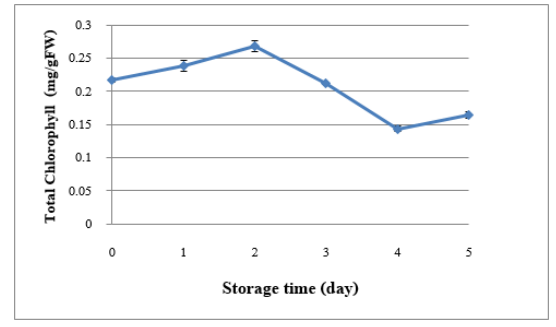

Fig. 3. Chlorophyll of controlled samples. 

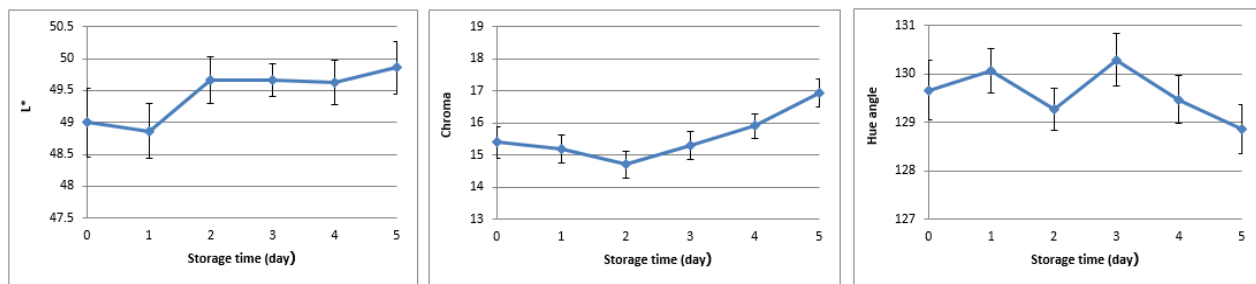

Fig. 4a, 4b, 4c. Colour change for controlled samples ( $\mathrm{L}^{*}$, Chroma and hue angle).

\subsection{Percentage of weight loss}

After exposing cos lettuce to high temperature at designated temperature and time, it was possible to indicate critical time for each expose temperature that cause the increment of weight loss percentage. At $25^{\circ}$ exposed temperature (Figure 5a), the weight loss percentage was less than $1.2 \%$ per day when the exposed time were 15 and $30 \mathrm{~min}$ while longer exposed time almost doubled percentage of weight loss. At $30^{\circ} \mathrm{C}$ exposed temperature (Figure 5b), the weight loss percentage was less than $1.35 \%$ per day when the exposed time was 15 min. Longer exposed time almost doubled percentage of weight loss as well. At $40^{\circ} \mathrm{C}$ exposed temperature (Figure $5 \mathrm{c}$ and $5 \mathrm{~d}$ ), there was no clearly different among any exposed time.

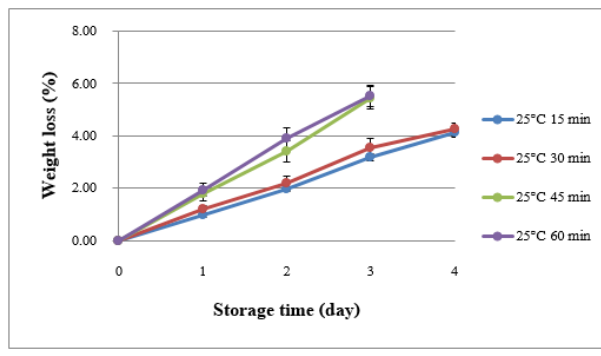

Fig. 5a. $\%$ weight loss for $25^{\circ} \mathrm{C}$ exposed temp.

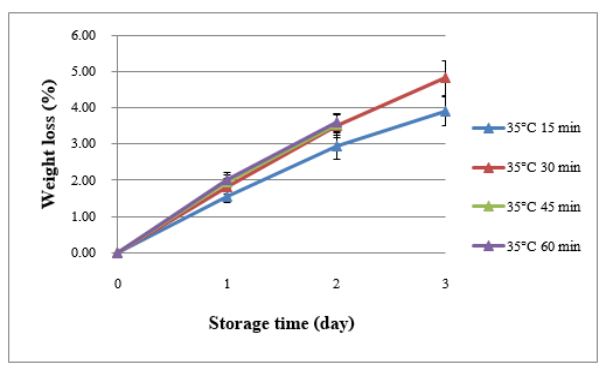

Fig. 5c. \% weight loss for $3^{\circ} \mathrm{C}$ exposed temp.

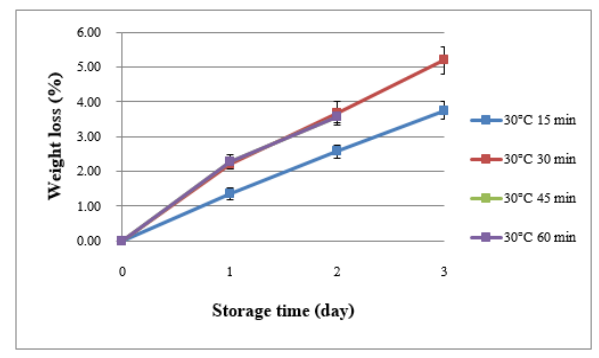

Fig. 5b. \% weight loss for $30^{\circ} \mathrm{C}$ exposed temp.

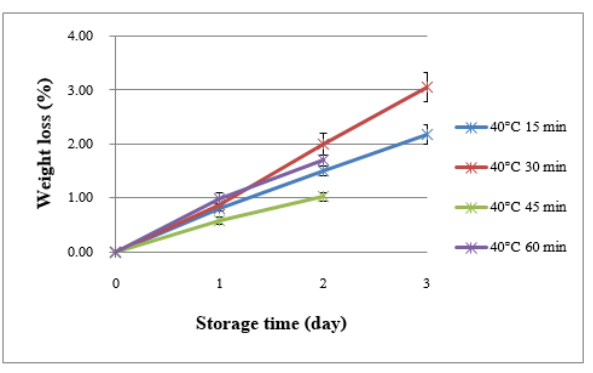

Fig. 5d. \% weight loss for $40^{\circ} \mathrm{C}$ exposed temp.

\subsection{Colour change}

According the controlled sample, the colour of cos lettuce would turn yellow and faded over time. Although the colour of cos lettuce leaves were different in each set of sample, the change of colour could refer to the effect from explosion to high temperature. The patterns of $\mathrm{L}^{*}$ in Figure $6 \mathrm{a}, 7 \mathrm{a}, 8 \mathrm{a}$ and $9 \mathrm{a}$ varied in small range of \pm 1.5 indicated that there was no fading effect occurred on the leaves. Pattern changes of Chroma and hue angle at $25^{\circ} \mathrm{C}$ exposed temperature varied in small range of \pm 2 (Figure $6 a-6 c$ ) indicating that the leaves of 
cos lettuce could maintain their colour shade and hue during storage time for all exposure time. On the other hand, at higher exposed temperatures. The leaves changed into yellow (Figure 7a-9c) according to the change of Chroma and hue angle into yellow zone of CIELAB colour diagram.
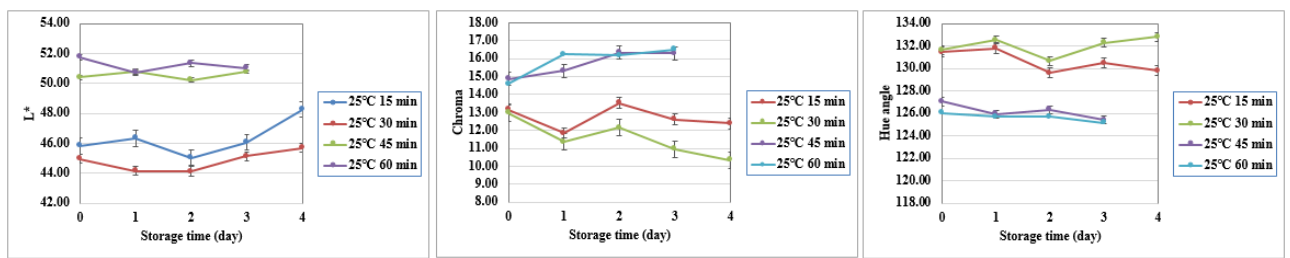

Fig. 6a, 6b, 6c. Colour change for $25^{\circ} \mathrm{C}$ exposed temp. (L*, Chroma and hue angle).
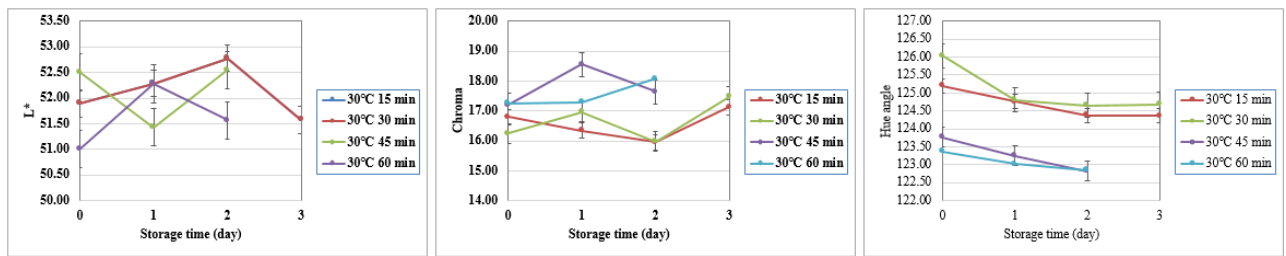

Fig. 7a, 7b, 7c. Colour change for $30^{\circ} \mathrm{C}$ exposed temp. (L*, Chroma and hue angle).
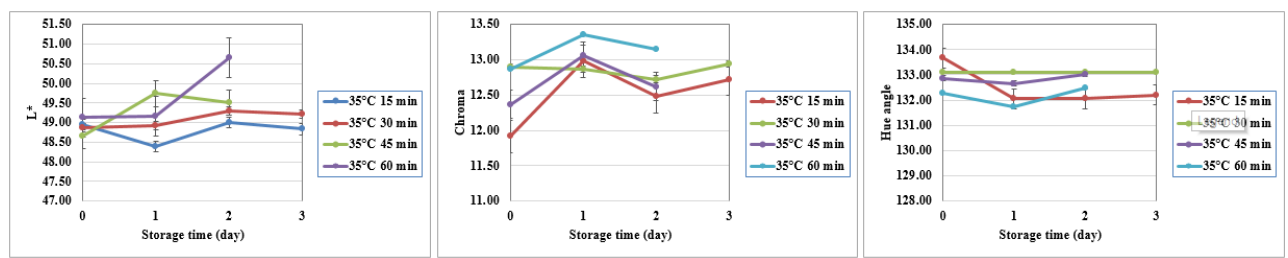

Fig. 8a, 8b, 8c. . Colour change for $35^{\circ} \mathrm{C}$ exposed temp. (L*, Chroma and hue angle).
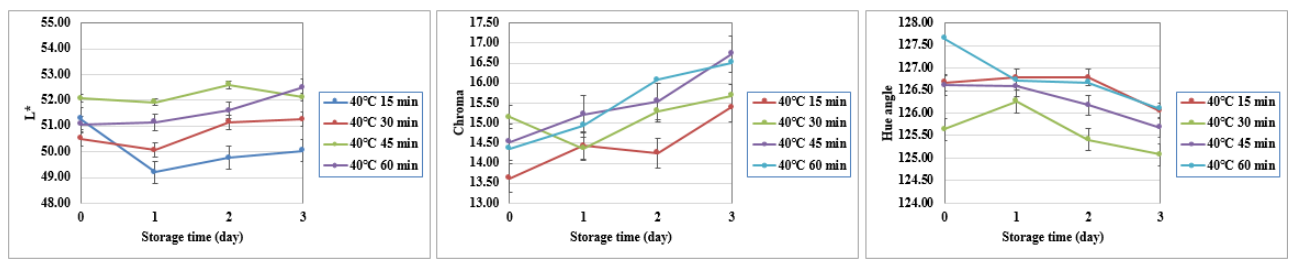

Fig. 9a, 9b, 9c. Colour change for $40^{\circ} \mathrm{C}$ exposed temp. (L*, Chroma and hue angle).

\subsection{Chlorophyll content}

The chlorophyll of green leaf was used as parameters of the quality of vegetables during storage, since it will be degraded gradually after harvesting [4]. By detecting chlorophyll content, it could represent the degradation in biological aspect of cos lettuce. Results of the experiment as shown in Figure 10a-10d presented 2 patterns of total chlorophyll changing. The pattern of increasing of chlorophyll occurred only for the exposure of temperature at $25^{\circ} \mathrm{C}$ for less than 30 min (Figure. 10a). Another pattern was in the rest of experiment conditions as shown in Figure $10 \mathrm{~b}-10 \mathrm{~d}$ and condition of temperature $25^{\circ} \mathrm{C}$ for longer than 30 min (Figure10a) in which revealed the stop the process of producing chlorophyll. 


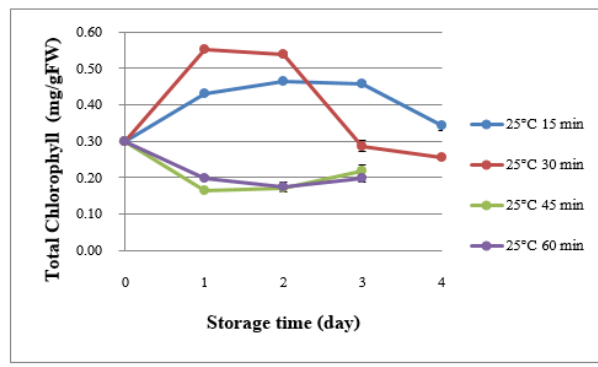

Fig. 10a. Chlorophyll for $25^{\circ} \mathrm{C}$ exposed temp.

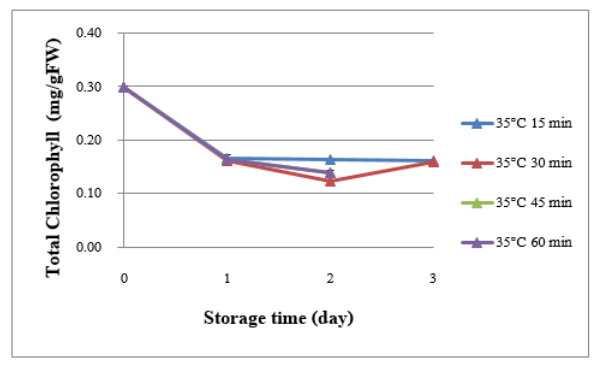

Fig. 10c. Chlorophyll for $35^{\circ} \mathrm{C}$ exposed temp.

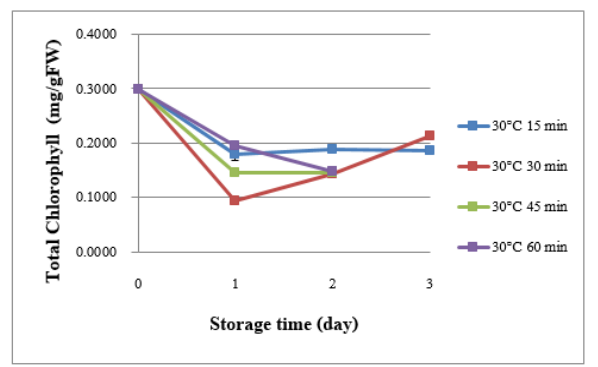

Fig. 10b. Chlorophyll for $30^{\circ} \mathrm{C}$ exposed temp.

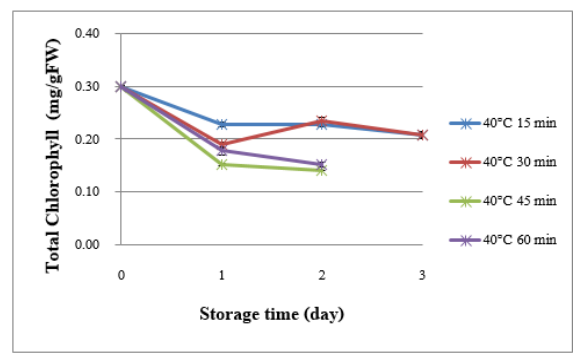

Fig. 10d. Chlorophyll for $40^{\circ} \mathrm{C}$ exposed temp.

\subsection{Product life}

Low temperatures are essential to extend product life of the perishable product [5] and high temperature would reduce its product life. Figure.11 clearly showed the exposing to high temperature could reduce cos lettuce physical quality and damage its appearance. Exposing to $25^{\circ} \mathrm{C}$ for $15 \mathrm{~min}$ was enough to reduce product life for 1 day. Higher temperature and longer time caused greater effect.

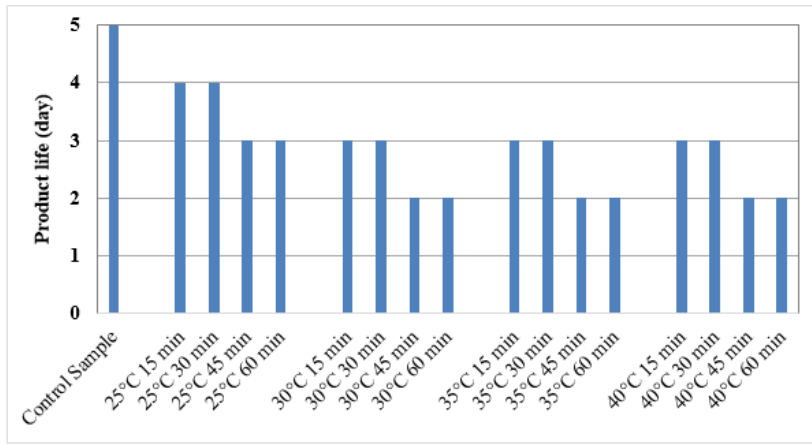

Fig. 11. Product life of cos lettuce exposed to high temperature.

\subsection{Effects of exposed high temperature to cos lettuce during cold chain system}

Temperature management throughout harvest and marketing chain is essential if quality of the product is to be assured [6]. Total continuous cold chain was the best condition for maintain cos lettuce's quality. When cos lettuce was exposed to high temperature, different 
damage levels occurred depending to exposed temperature and time. When a break of the cold chain was unavoidable, it is important to recognize the impact to the quality of cos lettuce. This information helped improve the management of the cold chain and ensured the quality of output to consumers.

Table 1. Limitation and good practices on discontinuity of cold chain on cos lettuce.

\begin{tabular}{|c|c|c|c|}
\hline $\begin{array}{l}\text { Exposed } \\
\text { Temp. }\end{array}$ & $\begin{array}{l}\text { Exposed } \\
\text { time }\end{array}$ & $\begin{array}{l}\text { Effects (compared to non-high-temperature- } \\
\text { exposed product) }\end{array}$ & Conclusion \\
\hline \multirow[t]{2}{*}{$25^{\circ} \mathrm{C}$} & $\begin{array}{l}\leq 30 \\
\min \end{array}$ & $\begin{array}{l}\text { - } \quad \text { Weight loss percentage did not increase. } \\
\text { - } \quad \text { Colour change occurred at the same rate. } \\
\text { - } \quad \text { Product life was reduced for } 1 \text { day. }\end{array}$ & $\begin{array}{l}\text { Small effect of } \\
\text { cos lettuce. }\end{array}$ \\
\hline & $\begin{array}{l}\geq 45 \\
\min \end{array}$ & $\begin{array}{l}\text { - } \quad \text { Weight loss percentage increased. } \\
\text { - } \quad \text { Leaf gradually turned yellow during storage. } \\
\text { - } \quad \text { Chlorophyll decreased after exposure. } \\
\text { - } \quad \text { Product life was reduced for } 2 \text { day. }\end{array}$ & $\begin{array}{l}\text { Reduce } \\
\text { product life } \\
\text { and qualities. }\end{array}$ \\
\hline \multirow[t]{3}{*}{$30^{\circ} \mathrm{C}$} & $\begin{array}{l}\leq 15 \\
\min \end{array}$ & $\begin{array}{ll} & \text { Weight loss percentage did not increase. } \\
\text { - } & \text { Leaf gradually turned yellow during storage. } \\
\text { - } & \text { Chlorophyll decreased after exposure } \\
\text { - } & \text { Product life was reduced for } 2 \text { day. }\end{array}$ & $\begin{array}{l}\text { Partially } \\
\text { reduce product } \\
\text { life and } \\
\text { qualities. }\end{array}$ \\
\hline & $30 \mathrm{~min}$ & $\begin{array}{l}\text { - } \quad \text { Weight loss percentage increased. } \\
\text { - } \quad \text { Leaf gradually turned yellow during storage. } \\
\text { - } \quad \text { Chlorophyll decreased after exposure } \\
\text { - } \quad \text { Product life was reduced for } 2 \text { day. }\end{array}$ & $\begin{array}{l}\text { Reduce } \\
\text { product life } \\
\text { and qualities. }\end{array}$ \\
\hline & $\begin{array}{l}\geq 45 \\
\min \end{array}$ & $\begin{array}{ll}\text { - } & \text { Weight loss percentage increased. } \\
\text { - } & \text { Leaf gradually turned yellow during storage. } \\
\text { - } & \text { Chlorophyll decreased after exposure } \\
\text { - } & \text { Product life was reduced for } 3 \text { day. }\end{array}$ & $\begin{array}{l}\text { Highly reduce } \\
\text { product life } \\
\text { and qualities. } \\
\text { Avoid. }\end{array}$ \\
\hline \multirow[t]{2}{*}{$35^{\circ} \mathrm{C}$} & $\begin{array}{l}\leq 15 \\
\text { min }\end{array}$ & $\begin{array}{l}\text { - } \quad \text { Weight loss percentage did not increase. } \\
\text { - } \quad \text { Leaf gradually turned yellow during storage. } \\
\text { - } \quad \text { Chlorophyll decreased after exposure } \\
\text { - } \quad \text { Product life was reduced for } 2 \text { day. }\end{array}$ & $\begin{array}{l}\text { Partially } \\
\text { reduce product } \\
\text { life and } \\
\text { qualities. } \\
\end{array}$ \\
\hline & $\begin{array}{l}\geq 30 \\
\min \end{array}$ & $\begin{array}{ll}\text { - } & \text { Weight loss percentage did not increase. } \\
\text { - } & \text { Leaf gradually turned yellow during storage. } \\
\text { - } & \text { Chlorophyll decreased after exposure } \\
\text { - } & \text { Product life was reduced for } 3 \text { day. }\end{array}$ & $\begin{array}{l}\text { Highly reduce } \\
\text { product life } \\
\text { and qualities. } \\
\text { Avoid. }\end{array}$ \\
\hline $40^{\circ} \mathrm{C}$ & $\begin{array}{l}\geq 15 \\
\min \end{array}$ & $\begin{array}{l}\text { - } \quad \text { Weight loss percentage increased. } \\
\text { - } \quad \text { Leaf gradually turned yellow during storage } \\
\text { and the leaf turned yellow rapidly. } \\
\text { - } \quad \text { Chlorophyll decreased after exposure } \\
\text { - } \quad \text { Product life was reduced for } 3 \text { day. }\end{array}$ & $\begin{array}{l}\text { Highly reduce } \\
\text { product life } \\
\text { and qualities. } \\
\text { Avoid. }\end{array}$ \\
\hline
\end{tabular}

\section{Conclusions}

Certain level of damage occurred to cos lettuce when cold chain temperature was disrupted. Product life, physical quality and biological activity of cos lettuce were reduced in reverse variation of exposed temperature and time. The experiment provided information on the level of damage at different exposed temperature and time for some indicator, such as product life, weight loss percentage, change of colour and change of chlorophyll. The information was useful for managing product transportation when high temperature exposure was unavoidable. 
Exposed temperature lower than $25^{\circ} \mathrm{C}$ for less than 30 min caused small effects on cos lettuce. Weight loss percentage increased by $0.2 \%$ compared with controlled sample. Colour change occurred at the same rate as controlled sample. Chlorophyll still increased after exposure. However, product life was reduced for 1 day. Longer exposed time caused higher rate of degradation. Exposed temperature at 30 and $35^{\circ} \mathrm{C}$ for less than $15 \mathrm{~min}$ also caused small effects on cos lettuce. Weight loss percentage increased by $0.35 \%$ compared with controlled sample. However, there was effect on colour leaves as they turned yellow and chlorophyll decreased at higher rate compared to controlled sample. Longer exposed time caused higher rate of degradation.

When atmospheric temperature was higher than $35^{\circ} \mathrm{C}$, the results on physical and chemical properties indicated high rate of weight loss, colour change, decrease of chlorophyll content and storage life after the exposure. Transporting process that might expose cos lettuce to atmospheric temperature should be avoid.

This research was supported by Postharvest Technology Innovation Center, Ministry of Higher Education, Science, Research and Innovation, Bangkok, Thailand.

\section{References}

1. Myo Min Aung and Yoon Seok Chang, Food Control 40, 198-207(2014)

2. Fei Tao, Min Zhang, Yu Hangqing, Sun Jincai, Journal of Food Engineering 77(3), 545549 (2006)

3. F.H. Witham, D.F. Blaydes, R.M. Devlin, Experiments in Plant Physiology (Van Nostrand, New York, 1971)

4. Leenawaty Limantaraa, Martin Dettling, Renny Indrawatia, Indriatmokoa, Tatas Hardo Panintingjati Brotosudarmo, Procedia Chemistry 14, 225 - 231(2015)

5. Maarten L. A. T. M. Hertog, Ismail Uysal, Ultan McCarthy, Bert M. Verlinden and Bart M. Nicolaï, A: Mathematical Physical and Engineering Sciences 372, rsta.2013.0306 (2014)

6. J. Jobling, Good Fruit and Vegetables Magazine 10(10), 30-31(2000) 